\title{
a \\ Level of follicular fluid vitamin D and embryo quality in a sample of Iraqi women undergoing IVF
}

\author{
DOI: https://doi.org/10.32007/med.1936/jfacmedbagdad.v60i4.7
}

\author{
Zainab M. Alawad* \\ MBChB, MSc
}

(4) 6 (i)

This work is licensed under a Creative Commons Attribution-NonCommercial 4.0 International License

\begin{abstract}
:
Background: Vitamin D has been linked to fertility since its receptors were found in reproductive organs. Nevertheless, its exact role in fertility is yet to be cleared.

Objectives: To analyze follicular fluid (FF) vitamin D in females doing Intracytoplasmic Sperm

J Fac Med Baghdad 2018; Vol.60, No.4 Received: Feb., 2019 Accepted: April, 2019 Published: May, 2019

Injection (ICSI), to compare its level between Polycystic Ovary Syndrome (PCOS) and non-PCOS females, and to explore whether vitamin D correlates with oocytes number, percentage of oocyte maturity, fertilization rate and percentage of high quality embryos.

Patients and methods: This comparative observational study was done, from January to October 2018, at Al Amal IVF Center, Jenin hospital, Baghdad. The study was conducted on 40 women; 18 had PCOS, 15 had blocked fallopian tubes and 7 had idiopathic infertility. FF vitamin D was analyzed by Ichroma kit, Boditech. Deficient, insufficient, and sufficient vitamin D levels were as: <10, 10-29, and 30-100 ng/ml, respectively.

Results: Most participants were deficient (12 women) or insufficient (18 women) of vitamin D, only 10 women had adequate vitamin D levels. FF vitamin D was higher in non-PCOS than PCOS women $(P=$ 0.011). The correlation between vitamin $\mathrm{D}$ and oocytes number was not significant. However, it was significant with percentage of oocyte maturity $(\mathrm{rho}=0.459, P=0.003)$, fertilization rate $(\mathrm{rho}=0.471, P=$ $0.002)$ and percentage of high quality embryos $(\mathrm{rho}=0.316, P=0.047)$.

Conclusions: PCOS patients, when compared to non-PCOS, have lower vitamin D levels. FF vitamin D might correlate with percentage of oocyte maturity, fertilization rate and percentage of high quality embryos in patients undergoing ICSI.

Keywords: Vitamin D, Follicular Fluid, In Vitro Fertilization, Intracytoplasmic Sperm Injection.
\end{abstract}

\section{Introduction:}

Vitamin D, a steroid hormone, is primarily formed by the skin when exposed to the sun. It is derived from daily intake of food such as dairy products, eggs, meat and fish (1). Vitamin D is important in keeping the physiological balance between calcium and phosphorus and in assisting bone mineralization (2). It also aids in decreasing risk of diabetes, cardiac and vascular abnormalities, malignancies and autoimmune disorders (3). Researches confirmed that the reproductive system in both genders contains vitamin D receptors, suggesting its role in reproductive physiology and fertility (4-7). Vitamin D deficiency is a universal issue (8). Reference values of vitamin D differ between researches (9-12). Some considered vitamin D level of less than $20 \mathrm{ng} / \mathrm{ml}$ as deficiency and level of 20$30 \mathrm{ng} / \mathrm{ml}$ as insufficiency whereas a level of more than $30 \mathrm{ng} / \mathrm{ml}$ being sufficient $(9,10)$, others suggest having vitamin D level of less than $10 \mathrm{ng} / \mathrm{ml}$ being deficient $(11,12)$. Categorization of follicular fluid vitamin D values may depend on serum criteria (12). Low vitamin $\mathrm{D}$ is common in reproductive age females (7). Vitamin D inadequacy was associated with infertility in animal and human studies $(6,13)$.

*Dept. of physiology, College of medicine,
University of Baghdad
Correspondence

Kinuta and team found that vitamin D receptor null mutant female mice developed impaired gonadal function, uterine hypoplasia, and abnormal folliculogenesis (6). In humans, research shows that vitamin $\mathrm{D}$ deficient women have a lower chance of being pregnant even with In vitro fertilization (IVF) (13). Evidence showed that $1 \mathrm{ng} / \mathrm{ml}$ increment in vitamin D level, raised the possibility of having pregnancy by $6 \%$ (9). Vitamin D regulates hormones involved in female reproduction. Those are: antiMüllerian hormone (AMH), follicle stimulating hormone (FSH), estradiol, and progesterone $(6,7)$. Calcitriol (active form of vitamin D), regulates genes involved in endometrial receptivity, mainly HOXA10 gene (5). It also regulates CYP19 gene that encodes aromatase enzyme (important in estradiol formation) (6). Studies showed alteration of vitamin D levels in disorders of reproductive organs (14-17). Some patients with uterine fibroids had been documented to have vitamin D insufficiency (14). Vitamin D association with endometriosis is still a controversial issue $(15,16)$. Chen et al, noticed that vitamin $\mathrm{D}$ deficiency accompanied by Interleukin 6 elevation might increase risk of tubal factor infertility (17). In Polycystic Ovary Syndrome (PCOS), the endocrine disorder with the highest prevalence in females of childbearing age (18), vitamin D deficiency is frequently present and it is involved in PCOS pathology via increasing parathyroid hormone (PTH) that resulted in 
menstrual abnormalities, anovulatory infertility, potentiation of hyperandrogenism and increasing insulin resistance (19) hence vitamin D insufficiency may increase severity of metabolic abnormalities in PCOS (20). Vitamin D possibly affects PCOS development through gene transcription (21). Studies examining vitamin D influence on embryo quality have been controversial $(12,22-24)$. Some observed that women having higher vitamin D, developed better quality embryos and achieved higher gestation rates than women having insufficient vitamin D $(22,23)$. Anifandis and team showed that vitamin D correlated negatively with embryo quality (24), whereas another research could not observe a relationship between vitamin $\mathrm{D}$ and chances of gestation (12). The aim of this study was to analyze follicular fluid (FF) vitamin D in females doing Intracytoplasmic Sperm Injection (ICSI), to compare its level between PCOS and non-PCOS patients and to investigate whether $\mathrm{FF}$ vitamin $\mathrm{D}$ correlates with oocytes number, percentage of oocyte maturity, fertilization rate and percentage of high quality embryos.

\section{Patients and Methods:}

A total of forty women, aged 25-40 years, were involved in this comparative observational study. They were divided, according to the cause of infertility, into PCOS patients (18 women) and nonPCOS patients (22 women). Fifteen of the nonPCOS women had tubal blockage and 7 had idiopathic infertility. The study was done at Al Amal IVF Center, Jenin hospital, Baghdad. It was done during the period between January 2018 and October 2018. The institutional ethical committee agreed on the research strategy and it was in agreement with the Helsinki Declaration of 1975, as revised in 2000. Informed consents were taken from the participants. Women with uterine anomalies, uterine fibroid, and endometriosis were excluded from this study. Demographic data and hormonal values of serum FSH, luteinizing hormone (LH), and prolactin were taken from patients' medical records. The participants received FSH injections (Gonal F, Merck Serono, or Fostimon, IBSA), in a short Gonadotropin-releasing hormone $(\mathrm{GnRH})$ antagonist protocol, FSH was initiated on day 2 of the menses, and the beginning dosage (75 IU or $150 \mathrm{IU}$ ) was determined according to the age of the participants, and levels of FSH day 2 or 3 of the menses. Stepdown or step-up protocols were used based on patient's ovarian response which was checked by sequential ultrasonic assessments and serum Estradiol (E2) analysis. When two follicles reached $17 \mathrm{~mm}$ or more in diameter, 5000 IU of Human chorionic gonadotropin (hCG) (Choriomon, IBSA or Pregnyl, Merck \& Co., Inc.) was given. After hCG by 36-37 hours, oocytes retrieval was performed using double lumen ovum aspiration needle (Cook, Australia). The procedure was guided by transvaginal ultrasound and the patients were given mild intravenous sedation. After collecting FF, oocytes were isolated, they were denuded, enzymatic denudation was done using Hyluronidase (Origio, Denmark) and mechanic denudation was performed by repeated pipetting. Assessment of oocytes maturity was done and they were classified as (germinal vesicle, MI and MII oocytes). Each MII oocyte was injected by a sperm. After ICSI procedure by 16-19 hours, oocytes were checked for pronuclei (PN) score. Only oocytes in which 2PN seen were considered to have normal fertilization. Fertilization rate was calculated as ratio of oocytes having $2 \mathrm{PN}$ to all injected oocytes. After cleavage of the fertilized oocytes, embryos were graded as grade1, 2, and 3 depending mainly on the size of the cells whether even or not and on fragmentation rate. Embryos were considered excellent (Grade 1) when day 2 embryos having 2-4 equal size blastomeres and day 3 embryos having 6-8 equal size blastomeres, both with fragmentation rate of $<10 \%$. Embryos were considered good (Grade 2) when day 2 embryos having 2-4 equal or unequal size blastomeres and day 3 embryos having 6-8 equal or unequal size blastomeres, both with fragmentation rate of $10 \%-20 \%$. Whereas embryos of poor quality (Grade 3) are those which had unequal and few blastomeres with $>20 \%$ fragmentation (25). In the current study, embryos of high quality included grade 1 and grade 2 embryos. Sydney IVF embryo transfer set (Cook medical, USA) was used to transfer embryos at day 2 or 3 of oocytes pickup. Woman's age and the availability of high quality embryos determined the number of transferred embryos. All participants received luteal phase support with vaginally administered progesterone (Crinone 8\%, Merck Serono). FF was collected from the follicles, and centrifuged at $3000 \mathrm{rpm}$ for 15 minutes using Hettich EBA 20 Benchtop Centrifuge. After that, all FF samples were clear. Each FF sample was frozen at $-20 \mathrm{C}^{\circ}$ then analyzed using (Ichroma kit, Boditech). Ichroma vitamin D along with Ichroma reader is a fluorescence immunoassay for the quantifiable identification of $25(\mathrm{OH})$ vitamin $\mathrm{D}$ with detection range of $8-70 \mathrm{ng} / \mathrm{ml}$. After putting the test cartridge into i- chamber, $50 \mu 1$ of releasing buffer was transferred into sample mixing tube. After that, $50 \mu \mathrm{l}$ of FF sample was transferred into sample mixing tube then mixing by pipetting for 10 times was done. Sample loaded tube was inserted into i- chamber at $35 \mathrm{C}^{\circ}$ for 5 minutes. $100 \mu \mathrm{l}$ of detection buffer was then added. Mixing was done again for 10 minutes and the tube was kept in ichamber at $35 \mathrm{C}^{\circ}$ for 15 minutes. Tube lock was fully inserted to trigger i- chamber timer. $75 \mu \mathrm{l}$ of whole mixture was dispensed on the sample well and then test cartridge was inserted into i- chamber and kept at $35 \mathrm{C}^{\circ}$ for 8 minutes. Sample loaded test cartridge was inserted into test cartridge holder, the select bottom in Ichroma reader was pressed and then vitamin D result appeared on the screen. FF vitamin D levels in this study were categorized depending on serum level criteria: deficient (less 
than $10 \mathrm{ng} / \mathrm{ml})$, insufficient $(10-29 \mathrm{ng} / \mathrm{ml})$ and sufficient (30-100 ng/ml) (12).

\section{Statistical analysis:}

For variables with normal distribution, this study applied Independent- Samples $\mathrm{T}$ test. While for variables with non-normal distribution, the study used Mann- Whitney $U$ test. For measuring the correlations between parameters, Spearman's rank correlation coefficient test was applied. A $P$ value < 0.05 was considered significant. All statistics were done using SPSS version 20 (IBM-USA).

\section{Results:}

This study was conducted on 40 women, undergoing ICSI, between 25 and 40 years of age. Eighteen women had PCOS as the cause of infertility and 22 women were non-PCOS patients. Of the non-PCOS women, 15 had blocked tubes and 7 had idiopathic infertility. Twenty women $(50 \%)$ had primary infertility and the other $50 \%$ had secondary infertility. According to FF vitamin D levels, most participants were either deficient (12 women had vitamin $D$ levels of less than $10 \mathrm{ng} / \mathrm{ml}$ ) or insufficient (18 women had vitamin D levels of 10$29 \mathrm{ng} / \mathrm{ml}$ ). Only 10 women had sufficient FF vitamin D levels of $30-100 \mathrm{ng} / \mathrm{ml}$. Age, Body mass index (BMI) and the duration of infertility were not significantly different between PCOS and nonPCOS women $(P=0.565, P=0.746$ and $P=0.240$ respectively), Table 1 . The table also shows the nonsignificant differences of FSH, LH and prolactin levels when both groups were compared $(P=0.490$, $P=0.104$, and $P=0.348$ respectively).

Table 1: Comparison of selected variables between the two groups

\begin{tabular}{|c|c|c|c|}
\hline Variables & $\begin{array}{l}\text { PCOS group } \\
(\mathrm{n}=18)\end{array}$ & $\begin{array}{l}\text { non-PCOS } \\
\text { group }(n=22)\end{array}$ & $P$ \\
\hline Age (years) & $31.9 \pm 4.65$ & $32.7 \pm 4.46$ & 0.565 \\
\hline BMI $\left(\mathrm{kg} / \mathrm{m}^{2}\right)$ & $28.3 \pm 4.29$ & $28.8 \pm 4.81$ & 0.746 \\
\hline $\begin{array}{l}\text { Duration of } \\
\text { infertility (years) }\end{array}$ & $4.8 \pm 1.43$ & $5.2 \pm 1.08$ & 0.240 \\
\hline FSH (mIU/ml) & $6.2 \pm 2.54$ & $6.7 \pm 2.40$ & 0.490 \\
\hline LH (mIU/ml) & $5.8 \pm 1.25$ & $5.1 \pm 1.29$ & 0.104 \\
\hline Prolactin $(\mathrm{ng} / \mathrm{ml})$ & $20.2 \pm 8.10$ & $17.4 \pm 9.86$ & 0.348 \\
\hline
\end{tabular}

FF vitamin D in the non-PCOS women showed higher levels than the PCOS patients ( $\mathrm{U}=104.500$, $P=0.011)$ as illustrated in Table 2 .
Table 2: FF vitamin D of PCOS and non-PCOS groups (Ranks and Test statistics)

\begin{tabular}{|c|c|c|c|c|}
\hline & Group & $\mathrm{N}$ & Mean rank & Sum of ranks \\
\hline \multirow{3}{*}{$\begin{array}{l}\text { FF } \\
\text { vitamin D } \\
(\mathrm{ng} / \mathrm{ml})\end{array}$} & PCOS & 18 & 15.31 & 275.50 \\
\hline & non-PCOS & 22 & 24.75 & 544.50 \\
\hline & Total & 40 & & \\
\hline
\end{tabular}

\begin{tabular}{ll}
\hline Test statistics & FF Vitamin D $(\mathrm{ng} / \mathrm{ml})$ \\
\hline Mann- Whitney U & 104.500 \\
\hline Wilcoxon W & 275.500 \\
\hline $\mathrm{Z}$ & -2.542 \\
\hline$P$ & 0.011 \\
\hline $\begin{array}{l}\mathrm{FF}=\text { follicular fluid, } \\
\text { number. }\end{array}$ &
\end{tabular}

Taking into consideration all participants in this study, correlations between FF vitamin D levels and several parameters were tested. No correlation was shown between vitamin D and FSH levels (Spearman's rho $=-0.057, P=0.725)$. However, significant negative correlations were noticed between FF vitamin D and LH levels (rho= -0.492 , $P=0.001)$ and between FF vitamin $\mathrm{D}$ and prolactin levels (rho $=-0.371, P=0.018)$, Table 3 .

Table 3: Correlations between FF vitamin $D$ and FSH, LH, and prolactin

\begin{tabular}{lll}
\hline & \multicolumn{2}{l}{ FF Vitamin D $(\mathrm{ng} / \mathrm{ml})$} \\
\hline Hormones & Rho & $P$ \\
\hline FSH $(\mathrm{mIU} / \mathrm{ml})$ & -0.057 & 0.725 \\
\hline LH $(\mathrm{mIU} / \mathrm{ml})$ & -0.492 & 0.001 \\
\hline Prolactin $(\mathrm{ng} / \mathrm{ml})$ & -0.371 & 0.018 \\
\hline FSH= Follicle-stimulating & hormone, LH= Luteinizing hormone,
\end{tabular}

$\mathrm{FF}=$ follicular fluid

Regarding ICSI outcomes, no significant correlation was shown between FF vitamin D and the number of retrieved oocytes (rho $=0.005, P=0.977$ ). However, significant positive correlations were found between FF vitamin D levels and percentage of oocyte maturity (rho $=0.459, P=0.003$ ), and between FF vitamin $D$ levels and fertilization rate $(\mathrm{rho}=0.471$, $P=0.002)$. Correlation between FF vitamin $\mathrm{D}$ and percentage of high quality embryo was significantly positive $(\mathrm{rho}=0.316, P=0.047)$, but with a lower level of significance compared to correlations of FF vitamin D levels with percentage of oocyte maturity and fertilization rate, Table 4.

Table 4: Correlations between FF vitamin D and ICSI outcomes

\begin{tabular}{lll}
\hline & \multicolumn{2}{l}{ FF Vitamin D $(\mathrm{ng} / \mathrm{ml})$} \\
\hline ICSI outcomes & Rho & $P$ \\
\hline Number of oocytes & 0.005 & 0.977 \\
\hline Oocyte maturity \% & 0.459 & 0.003 \\
\hline Fertilization rate \% & 0.471 & 0.002 \\
\hline High quality embryos \% & 0.316 & 0.047 \\
\hline FF= follicular fluid, ICSI= Intracytoplasmic sperm injection
\end{tabular}

\section{Discussion:}

This study compared FF vitamin D of PCOS versus non-PCOS females and investigated correlations between vitamin D and ICSI outcomes. The study noticed that despite the availability of sunshine in Iraq, most of the participants had low FF vitamin D levels. This may have resulted from seasonal 
variations in vitamin D concentrations (26) as the majority of the samples were collected in the winter or spring months. Furthermore, poor exposure to sunlight, and insufficient dietary consumption of vitamin D may have also contributed to these results. The study has shown that PCOS women have lower vitamin D levels than non-PCOS women, which is in agreement with the studies of Hamdi et al, and Mogili et al $(27,28)$. Vitamin D related polymorphisms could be the cause of its deficiency in PCOS (21). Deficiency of vitamin D in PCOS women, increases PTH thus potentiates the severity of PCOS (19). However, other studies could not show such variations in vitamin D between PCOS and non-PCOS women $(29,30)$. Studies are still inconsistent, and thus further research is needed.

It was proposed that low vitamin D levels in PCOS are caused by obesity that is largely associated with this syndrome (31), since vitamin D in obese women is trapped in adipose tissue causing low vitamin D levels in body fluids. However in this study, a nonsignificant difference was found between PCOS and non-PCOS regarding BMI, but still vitamin D level was significantly different between the groups being higher in the non-PCOS group. Vitamin D was inversely and significantly correlated with LH level. Deficiency of vitamin D might decrease aromatase activity in the ovary thus reduce progesterone and estradiol production by the follicles, which increases LH levels leading to alteration of folliculogenesis and ovulation. This agrees with the study of Solanki et al (32). Vitamin D and FSH levels showed nonsignificant correlation, the same finding was noticed by Shapiro et al (33). Prolactin was negatively and significantly correlated with vitamin D levels in this study, whereas another study found no correlation between prolactin and vitamin D (34). A nonsignificant correlation was shown between vitamin $\mathrm{D}$ levels and retrieved oocytes number, in agreement with other studies $(10,24)$. However, vitamin D levels correlated positively and significantly with percentage of oocyte maturity, fertilization rate and percentage of high quality embryos in this study. Vitamin D possibly alters AMH signaling and steroidogenesis in human cumulus granulosa cells (GCs) and thus improves follicle development (35). It was found that culturing immature human oocytes with GCs potentiates oocytes maturity and embryo development and that explains a possible link between GCs and oocyte maturity (35, 36). Moreover, studies done on mice with PCOS, found that vitamin D can modulate steroidogenesis in GCs, through activating AMP activated protein kinase (AMPK) signaling pathway, and thus improves follicle maturation in PCOS $(37,38)$. Vitamin D might regulate cellular oxidative stress in GCs, and thus may have an essential role in follicle development (39). These findings might give an explanation of the role of vitamin $\mathrm{D}$ in oocyte maturation. Mature oocytes have a better chance to be fertilized and form good quality embryos, and it was suggested that high pregnancy rate might have resulted from higher embryo quality in women having sufficient vitamin D levels (22). However, other studies have contradicting results concerning vitamin D levels and embryo quality as Anifandis et $a l$, noticed a negative correlation between vitamin D levels and quality of the embryos (24) and another recent study noticed that $\mathrm{FF}$ vitamin $\mathrm{D}$ correlates negatively with oocytes quality and that the oocytes with higher FF vitamin $\mathrm{D}$ are less able to be fertilized and they produce lower embryo quality than oocytes with low FF vitamin D levels (40). The discrepancy in the results of different studies could be explained by the fact that embryo quality depends on many factors including sperm quality and quantity, and not merely on oocyte condition.

\section{Limitations:}

The limitations include the relatively small participant's number and the use of pooled FF samples rather than following each individual follicle. It is recommended to do research including all ethnic and racial groups, and to involve more participants.

\section{Conclusions:}

Low vitamin D level is common even in sunny countries as most participants were having either vitamin D deficiency or insufficiency. PCOS patients have lower vitamin D levels in comparison to non-PCOS women. Vitamin D might correlate with embryo quality in patients undergoing ICSI. Evaluating vitamin D in infertility patients is essential, especially in PCOS women.

\section{References:}

1. Nowson CA, Margerison C. Vitamin D intake and vitamin D status of Australians. Med J Aust. 2002;177(3):149-52.

2. Jurutka PW, Bartik L, Whitfield GK, Mathern DR, Barthel TK, Gurevich $M$, et al. Vitamin D receptor: key roles in bone mineral pathophysiology, molecular mechanism of action, and novel nutritional ligands. $J$ Bone Miner Res. 2007;22(Suppl 2): V2-V10.

3. Holick MF. Vitamin D: important for prevention of osteoporosis, cardiovascular heart disease, type 1 diabetes, autoimmune diseases, and some cancers. South Med J. 2005;98(10):1024-8.

4. Blomberg Jensen M, Nielsen JE, Jørgensen A, Rajpert-De Meyts E, Kristensen DM, Jørgensen N, et al. Vitamin $D$ receptor and vitamin $D$ metabolizing enzymes are expressed in the human male reproductive tract. Hum Reprod. 2010;25(5):1303-11.

5. Daftary GS, Taylor HS. Endocrine regulation of HOX genes. Endocr Rev. 2006;27(4):331-55.

6. Kinuta K, Tanaka H, Moriwake T, Aya K, Kato $S$, Seino $Y$. Vitamin $D$ is an important factor in estrogen biosynthesis of both female and male gonads. Endocrinology. 2000;141(4):1317-24.

7. Irani $M$, Merhi Z. Role of vitamin $D$ in ovarian physiology and its implication in reproduction: a systematic review. Fertil Steril. 2014;102(2):460-8. 
8. Cashman KD, Dowling $K G$, Škrabáková Z, Gonzalez-Gross M, Valtueña J, De Henauw S, et al. Vitamin D deficiency in Europe: pandemic?. Am J Clin Nutr. 2016;103(4):1033-44.

9. Ozkan S, Jindal S, Greenseid K, Shu J, Zeitlian $G$, Hickmon $C$, et al. Replete vitamin $D$ stores predict reproductive success following in vitro fertilization. Fertil Steril. 2010;94(4):1314-19.

10. Rudick $B$, Ingles $S$, Chung $K$, Stanczyk $F$, Paulson $R$, Bendikson $K$. Characterizing the influence of vitamin D levels on IVF outcomes. Hum Reprod. 2012;27(11):3321-27.

11. Blomberg Jensen M, Bjerrum PJ, Jessen TE, Nielsen JE, Joensen UN, Olesen IA, et al. Vitamin D is positively associated with sperm motility and increases intracellular calcium in human spermatozoa. Hum Reprod. 2011;26(6):1307-17.

12. Firouzabadi RD, Rahmani E, Rahsepar $M$, Firouzabadi MM. Value of follicular fluid vitamin $D$ in predicting the pregnancy rate in an IVF program. Arch Gynecol Obstet. 2014;289(1):201-6.

13. Chu J, Gallos I, Tobias A, Tan B, Eapen A, Coomarasamy A. Vitamin $D$ and assisted reproductive treatment outcome: a systematic review and meta-analysis. Hum Reprod. 2017;33(1):65-80. 14. Sersam LW, Najeeb SF. Serum Vitamin D3 Levels in Women with and without Uterine Fibroids. IPMJ. 2018;17(3):239-48.

15. Somigliana E, Panina-Bordignon P, Murone S, Di Lucia P, Vercellini P, Vigano P. Vitamin D reserve is higher in women with endometriosis. Hum Reprod. 2007;22(8):2273-8.

16. Ciavattini A, Serri M, Delli Carpini G, Morini S, Clemente N. Ovarian endometriosis and vitamin $D$ serum levels. Gynecol Endocrinol. 2017;33(2):1647.

17. Chen W, Jiao X, Zhang J, Wang L, Yu X. Vitamin $D$ deficiency and high serum IL-6 concentration as risk factors for tubal factor infertility in Chinese women. Nutrition. 2018;49:24-31.

18. Ahmed HS, Abbas AK. The Relationship between Reproductive Hormones and Metabolic Parameters in Women with Polycystic Ovary Syndrome. J Fac Med Baghdad. 2014;56(2):234-38.

19. Thomson RL, Spedding S, Buckley JD. Vitamin D in the aetiology and management of polycystic ovary syndrome. Clin Endocrinol. 2012;77(3):343-50.

20. Kumar A, Barki S, Raghav V, Chaturvedi A, Kumar KH. Correlation of Vitamin D with metabolic parameters in polycystic ovarian syndrome. J Family Med Prim Care. 2017;6(1):115-9.

21. Mahmoudi T. Genetic variation in the vitamin $D$ receptor and polycystic ovary syndrome risk. Fertil Steril. 2009;92(4):1381-3.

22. Garbedian K, Boggild M, Moody J, Liu KE. Effect of vitamin $D$ status on clinical pregnancy rates following in vitro fertilization. CMAJ open. 2013;1(2):E77-82.

23. Paffoni A, Ferrari S, Viganò P, Pagliardini L, Papaleo E, Candiani $M$, et al. Vitamin D deficiency and infertility: insights from in vitro fertilization cycles. J Clin Endocrinol Metab. 2014;99(11):E2372-6.

24. Anifandis GM, Dafopoulos K, Messini CI, Chalvatzas $N$, Liakos $N$, Pournaras $S$, et al. Prognostic value of follicular fluid 25-OH vitamin D and glucose levels in the IVF outcome. Reprod Biol Endocrinol. 2010;8:91.

25. Hassani F, Eftekhari-Yazdi $P$, Karimian L, Valojerdi MR, Movaghar B, Fazel M, et al. The effects of ISMI medium on embryo quality and outcomes of IVF/ICSI cycles. Int J Fertil Steril. 2013;7(2):108-115.

26. Issa AM, Ibraheem SA. Alterations of vitamin" $D^{\prime \prime}$ level in sera of Iraqi population. JKU. 2007;5(1):58-64.

27. Hamdi RA, Abdul-Qahar ZH, Kadhum EJ, Alsaeed FA. Assessment of Serum Vitamin D Levels in Women with Polycystic Ovary Syndrome. J Fac Med Baghdad. 2018;60(2):93-7.

28. Mogili KD, Karuppusami R, Thomas S, Chandy A, Kamath MS, Aleyamma TK. Prevalence of vitamin $D$ deficiency in infertile women with polycystic ovarian syndrome and its association with metabolic syndrome-A prospective observational study. Eur J Obstet Gynecol Reprod Biol. 2018;229:15-9.

29. Kim JJ, Choi YM, Chae SJ, Hwang KR, Yoon SH, Kim MJ, et al. Vitamin D deficiency in women with polycystic ovary syndrome. Clin Exp Reprod Med. 2014;41(2):80-5.

30. Naderpoor N, Shorakae S, Abell SK, Mousa A, Joham AE, Moran LJ, et al. Bioavailable and free 25-hydroxyvitamin $D$ and vitamin $D$ binding protein in polycystic ovary syndrome: Relationships with obesity and insulin resistance. J Steroid Biochem Mol Biol. 2018;177:209-15.

31. Muscogiuri G, Policola C, Prioletta A, Sorice G, Mezza T, Lassandro A, et al. Low levels of $25(\mathrm{OH})$ $D$ and insulin-resistance: 2 unrelated features or $a$ cause-effect in PCOS?. Clin Nutr. 2012;31(4):47680.

32. Solanki V, Chaurasia A, Singh S, Sachan S, Varma K, Devi R. Estimation of serum 25 hydroxy vitamin $D$ level and its correlation with metabolic and endocrine dysregulation in women with PCOS. Int $J$ Reprod Contracept Obstet Gynecol. 2017;6(7):3085-90.

33. Shapiro AJ, Darmon SK, Barad DH, Gleicher N, Kushnir VA. Vitamin D levels are not associated with ovarian reserve in a group of infertile women with a high prevalance of diminished ovarian reserve. Fertil Steril. 2018;110(4):761-6.e1.

34. Awad MM, Ismail AM. Assessment of Prolactin level in Vitamin D Deficiency Type-2 Diabetes Mellitus Patients. NJST. 2017;1(1):34-8.

35. Merhi Z, Doswell A, Krebs K, Cipolla M. Vitamin $D$ alters genes involved in follicular development and steroidogenesis in human cumulus granulosa cells. J Clin Endocrinol Metab. 2014;99(6): E1137-45.

36. Jahromi BN, Mosallanezhad Z, Matloob N, Davari M, Ghobadifar MA. The potential role of 
granulosa cells in the maturation rate of immature human oocytes and embryo development: A coculture study. Clin Exp Reprod Med. 2015;42(3):111-7.

37. Bakhshalizadeh S, Amidi F, Alleyassin A, Soleimani $M$, Shirazi $R$, Shabani Nashtaei $M$. Modulation of steroidogenesis by vitamin D3 in granulosa cells of the mouse model of polycystic ovarian syndrome. Syst Biol Reprod Med. 2017;63(3):150-61.

38. Bakhshalizadeh S, Amidi F, Shirazi R, Shabani Nashtaei M. Vitamin D3 regulates steroidogenesis in granulosa cells through AMP-activated protein kinase (AMPK) activation in a mouse model of polycystic ovary syndrome. Cell Biochem Funct. 2018;36(4):183-93.

39. Yao X, Zhang G, Guo Y, Mohamed ES, Wang S, Wan $Y$, et al. Vitamin $D$ receptor expression and potential role of vitamin $D$ on cell proliferation and steroidogenesis in goat ovarian granulosa cells. Theriogenology. 2017; 102:162-73.

40. Ciepiela P, Dulęba AJ, Kowaleczko E, Chetstowski K, Kurzawa R. Vitamin D as a follicular marker of human oocyte quality and a serum marker of in vitro fertilization outcome. J Assist Reprod Genet. 2018;35(7):1265-76. 
مستوى فيتامين د في السائل الجريبي وجودة الجنين في عينة من النساء العراقيات اللواتي يخضعن لعمليات التخصيب المختبري

\section{د. دينب مثنى العواد}

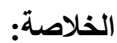

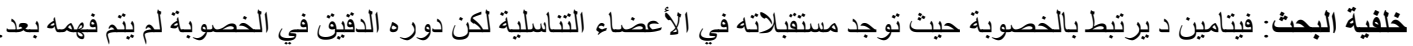

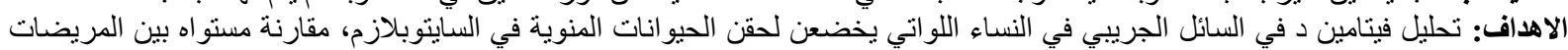

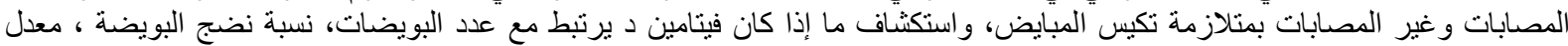

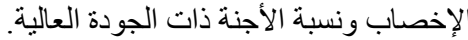

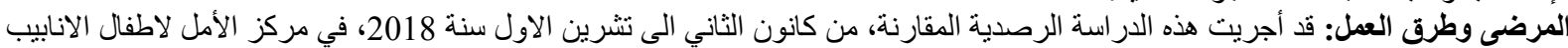

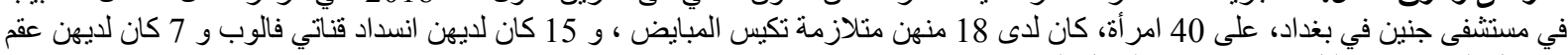

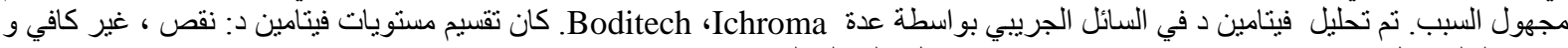

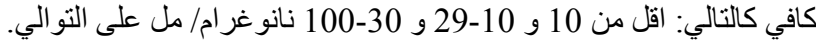

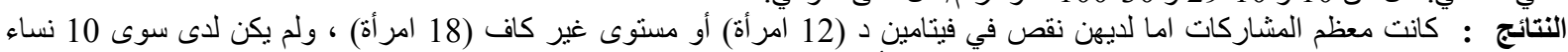

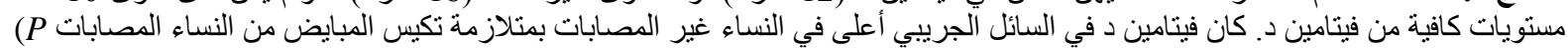

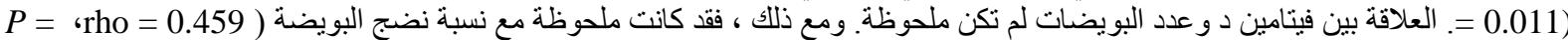

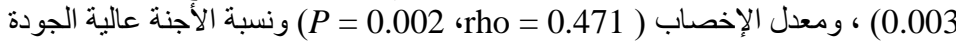
(P=0.047 rho = 0.316$)$

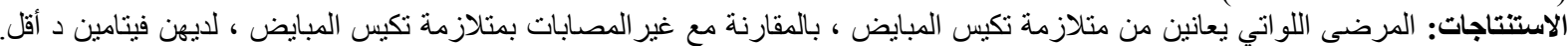

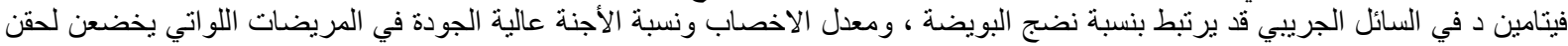

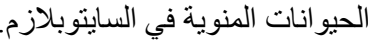
مفتاح الكلمات: فيتامين د، السائل الجريبي، التخصيب النيب المختبري، حقن الحيو انات المنوية في السايتوبلازم. 